\title{
INTEGRASI OPEN DATA, URUN DAYA, DAN PEMETAAN PARTISIPATIF DALAM PENGELOLAAN SUMBER DAYA ALAM DAN LINGKUNGAN HIDUP \\ Integration of Open Data, Crowdsourcing, and Participatory Mapping for Natural Resources and Environmental Management
}

\author{
Moh. Dede ${ }^{1}$, Asep Mulyadi², Millary Agung Widiawaty ${ }^{2}$ \\ ${ }^{1}$ Program Magister Ilmu Lingkungan, SPs, Universitas Padjadjaran, Kota Bandung, Indonesia \\ ${ }^{2}$ Departemen Pendidikan Geografi, FPIPS, Universitas Pendidikan Indonesia, Kota Bandung, Indonesia \\ Email Korespondensi: m.dede.geo@gmail.com
}

DOI: $10.31314 /$ jsig.v3i2.659

Abstract - Data and information availability area main obstacles in the natural resources and environmental (SDAL) management in developing countries. Technology development in society should be able to support SDAL management to be more efficient and effective while empowering the local human resources through open data, crowdsourcing, and participatory mapping. This article aims to explain the integration scheme of open data, crowdsourcing, and participatory mapping in SDAL management. The integration can be initiated by utilizing open data freely available through many institution websites as basic data and information. The essential shortcoming of open data in terms of accuracy and updating can be overcome through crowdsourcing. Voluntary involvement in collecting data and information is a key characteristic of crowdsourcing. The results of the crowdsourcing activities are collected online through a social media platform or organizer page. The quality of the data and information is very influenced by the socialization of organizers, assistive media installation, and devices used by society. More detailed data and information needs can be obtained through participatory mapping where the implementation must begin with technical training for society and parties involved. Open data, participatory mapping, and participatory mapping can be integrated using GIS or non-spatial analysis because of similarities such as a passion for sharing, community empowerment, giving more value to data and information, cost and time efficiency, and openness.

Keywords: GIS, natural resources and environmental management, open data, participatory mapping.

\begin{abstract}
Abstrak - Ketersediaan data dan informasi merupakan salah satu kendala utama dalam pengelolaan sumber daya alam dan lingkungan (SDAL) di negara-negara berkembang. Padahal perkembangan teknologi di tengah masyarakat seharusnya mampu mendukung kegiatan pengelolaan SDAL menjadi lebih efisien dan efektif, sekaligus memberdayakan potensi sumber daya manusia setempat melalui open data, urun daya, dan pemetaan partisipatif. Artikel ini bertujuan untuk menjelaskan skema integrasi open data, urun daya, dan pemetaan partisipatif dalam pengelolaan SDAL. Integrasi ketiganya dapat diawali dengan memanfaatkan open data yang tersedia bebas melalui laman daring beragam instansi sebagai data dan informasi dasar. Keterbatasan utama open data yakni dari segi ketelitian serta updating bisa ditanggulangi melalui kegiatan urun daya. Pelibatan masyarakat secara sukarela dalam proses pengumpulan data dan informasi terkait SDAL merupakan ciri utama urun daya. Hasil kegiatan urun daya dikumpulkan secara daring melalui platform jejaring sosial maupun laman penyelenggara. Kualitas data dan informasinya sangat dipengaruhi oleh sosialisasi dari penyelenggara, pemasangan media bantu, dan perangkat yang digunakan oleh masyarakat. Kebutuhan data dan informasi lebih rinci dapat diperoleh melalui kegiatan pemetaan partisipatif yang mana pelaksanaannya harus diawali dengan pelatihan teknis bagi masyarakat dan pihak terlibat. Open data, urun daya, dan pemetaan partisipatif dapat diintegrasikan karena adanya kesamaan seperti semangat untuk berbagi, pemberdayaan masyarakat, pemberian nilai lebih terhadap data dan informasi, efisiensi biaya dan waktu, serta keterbukaan.
\end{abstract}

Kata kunci: open data, pemetaan partisipatif, pengelolaan SDAL, SIG, urun daya. 


\section{PENDAHULUAN}

Sumber daya merupakan segala sesuatu yang memiliki nilai guna dan dapat dimanfaatkan untuk memenuhi beragam kebutuhan manusia. Berdasarkan asal usulnya, sumber daya terbagi atas sumber daya alam (SDA) dan sumber daya manusia (SDM). SDA dikenal sebagai semua yang berasal dari sistem geosfer dan dapat terus eksis secara alamiah tanpa campur tangan manusia (Miller \& Spoolman, 2011; Christanto, 2014). Kebutuhan manusia dan ketersediaan SDA merupakan dua hal yang saling bertolak belakang. SDA memiliki sifat terbatas yang berbanding terbalik dengan kebutuhan manusia yang cenderung tak terbatas, terlebih bila unsur desires turut andil dan berperan lebih dominan hingga menghasilkan beragam kerusakan lingkungan (Hendawati, 2012). SDA dapat pula dipahami sebagai kombinasi dari elemenelemen hayati dan non-hayati di sekitarnya yang membentuk suatu ekosistem, sehingga istilah SDA dan lingkungan hidup merupakan dua entitas tak terpisahkan sebagai satu kesatuan (Kehati, 2009).

Sumber daya alam dan lingkungan (SDAL) memiliki peranan utama dalam kegiatan pembangunan dan keberlanjutan hidup manusia, baik dalam penyediaan kebutuhan pangan, energi, maupun sebagai penyangga sistem kehidupan. Keberadaan SDAL perlu dikelola secara bijak agar manfaat dan kelestariannya berjalan beriringan, dimana level pemanfaatannya akan selalu sebanding dengan risikonya (Soemarwoto, 1985). Di Indonesia, pengelolaan SDAL telah diatur oleh konstitusi dalam rangka mewujudkan kesejahteraan umum dan keadilan sosial yang seluruh elemen bangsa dapat turut serta memanfaatkannya (GN-PSDA, 2015). Sebagai rangkaian dari ikhtiar manusia dalam memberdayakan bumi, ruang lingkup pengelolaan SDAL meliputi kegiatan perencanaan, pelaksanaan dan pemanfaatan, serta pengawasan yang semuanya memerlukan data dan informasi mumpuni dalam rangka proses pengambilan keputusan. Pada era desentralisasi, kewenangan pengelolaan SDAL telah diberikan seluasluasnya pada masing-masing daerah. Pemberian wewenang dari pemerintah pusat kepada daerah dilandasi oleh keyakinan bahwa potensi SDAL lokal dapat dipahami dengan lebih baik oleh stakeholder setempat. Meskipun tantangan teoretis dan teknis kembali muncul akibat kurangnya kesiapan SDM untuk memperoleh data dan informasi yang diperlukan terkait SDAL, sehingga identifikasi potensinya tidak dapat diketahui dengan jelas (Habibullah, 2007).

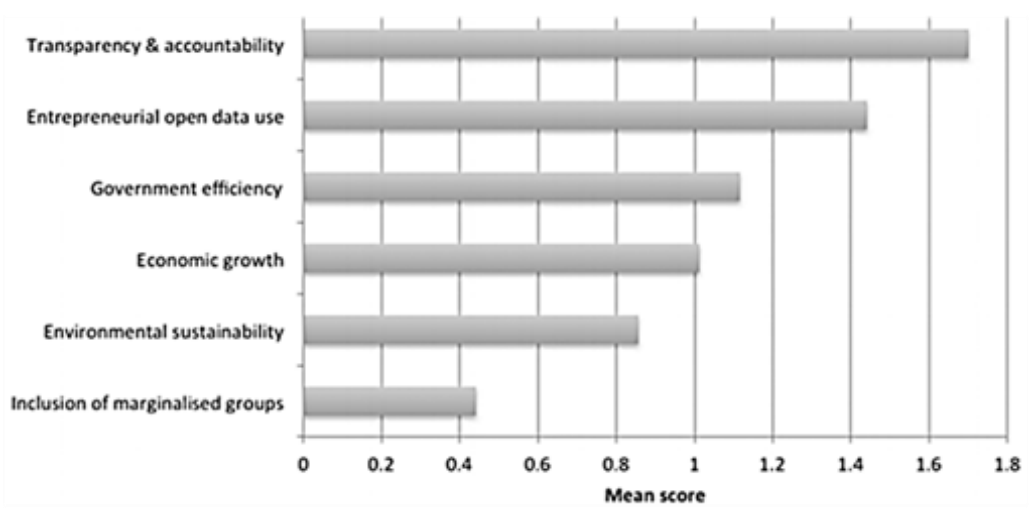

Gambar 1. Dampak Penggunaan Open Data di Berbagai Bidang. (Sumber: Open Data Watch, 2018)

Adanya paradigma bahwa pengumpulan data dan informasi untuk pengelolaan SDAL yang mahal, sulit, lama, serta memerlukan banyak tenaga ahli, sering kali memicu pemerintah daerah enggan untuk melakukan kegiatan tersebut. Akibatnya data dan informasi yang tersedia menjadi kedaluarsa, tidak sesuai kebutuhan, bahkan tidak memenuhi standar minimal yang ditetapkan oleh pemerintah pusat. Kondisi ini memicu multiplier effect yang bersifat negatif di bidang pengelolaan SDAL, padahal dinamika lingkungan kian memicu para pengambil keputusan untuk cepat tanggap demi kemanusiaan. Salah satu solusi untuk menanggulangi kondisi ini adalah integrasi pemanfaatan open data, urun daya, dan pemetaan partisipatif (Gambar 1). Open data dapat memenuhi kebutuhan fundamental terkait pengelolaan SDAL. Menurut Widiawaty (2019), open data tersedia secara daring melalui laman-laman resmi milik lembaga pemerintah dan non-pemerintah, dimana mayoritas dataset-nya dapat diunduh dan 
dimanfaatkan secara gratis. Pemanfataan open data dalam pengelolaan SDAL perlu dilakukan secara bijak, karena terikat dengan lisensi, waktu, ketelitian, dan ekstesinya. Berbagai keterbatasan terkait sifat dan karakteristik open data dapat ditanggulangi melalui urun daya dan pemetaan partisipatif, terlebih bila pemanfataanya dapat diolah dengan sistem informasi geografis (SIG) yang didukung oleh perangkat lunak gratis dan bersumber terbuka (FOSS).

Pemanfaatan secara parsial dari ketiganya sudah lazim dilakukan oleh banyak negara dan menjadi salah satu opsi terbaik, karena dapat diaplikasikan sesuai dengan kebutuhan dan karakteristik lingkungan setempat (Ar-Rahiem, 2019). Integrasi open data, urun daya, dan pemetaan partisipatif merupakan solusi dalam pemenuhan data dan informasi, sekaligus sebagai bagian untuk memberdayakan masyarakat, asalkan pemerintah dan masyarakat mampu bekerja sama dengan perguruan tinggi, akademisi, maupun peneliti yang kredibel agar menemukan upaya dan cara tepat untuk menguak beragam potensi SDAL beserta potensi keberlanjutannya (Widiawaty, 2019; Amaru, Asdak \& Balia, 2013; Badiee, 2017). Integrasi ketiganya memiliki efektifitas dan efisiensi tinggi dari segi waktu, biaya, alat dan teknologi, maupun pengerahan SDM. Integrasi ini juga dapat menumbuhkan wawasan dan keterampilan masyarakat setempat agar mampu memanfaatkan teknologi informasi yang tersedia untuk mengenali potensi SDAL dengan lebih baik. Oleh sebab itu, penulisan artikel ini dimaksudkan untuk menjelaskan skema integrasi open data, urun daya, dan pemetaan partisipatif dalam pengelolaan sumber daya alam dan lingkungan. Hal ini dilandasi adanya peningkatan kebutuhan data dan informasi terkait SDAL di tengah keterbatasan yang sering dialami oleh negara-negara berkembang untuk beragam analisis dan proses pengambilan keputusan. Upaya ini sekaligus menjadi upaya untuk meningkatkan kompetensi masyarakat setempat sebagai subjek pembangunan. Kajian mengenai topik ini dilandasi atas telaah literatur dan pengalaman penulis dalam memanfaatkan ketiganya untuk berbagai kepentingan akademik, ilmiah maupun pengabdian pada masyarakat.

\section{INTEGRASI OPEN DATA, URUN DAYA, DAN PEMETAAN PARTISIPATIF}

Open data merupakan sebagai segala bentuk data dan informasi yang tersedia bebas untuk pengguna secara inklusif. Open data memiliki fleksibilitas untuk digunakan, disebarluaskan, dan dipergunakan kembali mengingat data dan informasi dapat dinyatakan terbuka apabila tidak ada batasan dalam ranah publik maupun privat, bahkan untuk kegiatan komersial sekalipun sebagai bagian dari partisipasi universal (Wijaya, 2014; Young \& Verhulst, 2016). Prinsip utama dalam pemanfaatan open data hanyalah keharusan untuk menyebutkan pihak pembuatnya dan membagikannya kembali dengan lisensi yang sama, misalnya Creative Commons Attribution Share Alike 2.0. Menurut Dietrich et al. (2009), open data memiliki sifat utama berupa interoperability yang diartikan sebagai kemampuan dari berbagai sistem atau organisasi untuk saling bekerja sama untuk menghasilkan dan mengolah antar basis data yang berbeda-beda. Interoperability akan menghasilkan data berukuran besar dan kompleks, tetapi akan tetap sesuai dengan standardisasi.

Di berbagai negara termasuk Indonesia, open data biasa disediakan oleh lembagalembaga resmi milik pemerintah maupun non-pemerintah melalui beragam portal daring sejak tahun 2011, pemanfaatannya diatur dalam Undang-Undang Nomor 14 Tahun 2008 tentang Keterbukaan Informasi Publik (JMC IT, 2019). Secara umum open data menyediakan data dan informasi bertipe atribut maupun bereferensi geografis, sehingga peranan pengolahannya secara spasial dapat dilakukan. Data dan informasi terkait pengelolaan SDAL dapat ditemui pada laman milik Badan Informasi Geospasial (BIG), Kementerian Lingkungan Hidup dan Kehutanan RI (KLHK), Lembaga Penerbangan dan Antariksa Negara (LAPAN), Badan Meteorologi Klimatologi dan Geofisika (BMKG), Kementerian Pertanian RI (Kementan), Kementerian Kelautan dan Perikanan RI (KKP), serta Badan Pusat Statistik (BPS). Selain itu, open data dapat berasal dari lembaga-lembaga non-pemerintah, lembaga internasional, maupun instansi negara lain, contohnya Earth Explorer (USGS), Opentopography, dan Openstreetmap (OSM) (Widiawaty \& Dede, 2018; Misra, Avtar \& Takeuchi, 2018). Meski menyediakan data yang beragam dan berkualitas, kehadiran open data bukan berarti bebas akses. Sebagian open data tersimpan dalam bentuk format tertutup dan relatif sulit diakses, sehingga diperlukan beragam syarat (term and conditions), kepatutan, pengetahuan, serta keterampilan khusus pengguna untuk memanfaatkannya (Sidauruk \& Hamdi, 2015; Neupane et al., 2017). Selain itu, open data juga dapat tersirat dalam dokumentasi dan laporan tahunan asalkan penggunaan 
kembali maupun transformasinya tetap menyebutkan sumber asalnya di beragam bidang seperti kependudukan, pertanian, kesehatan, lingkungan hidup, kelautan, ekonomi, bahkan kejahatan (Dede, et al, 2019; Ismail, et al., 2020).
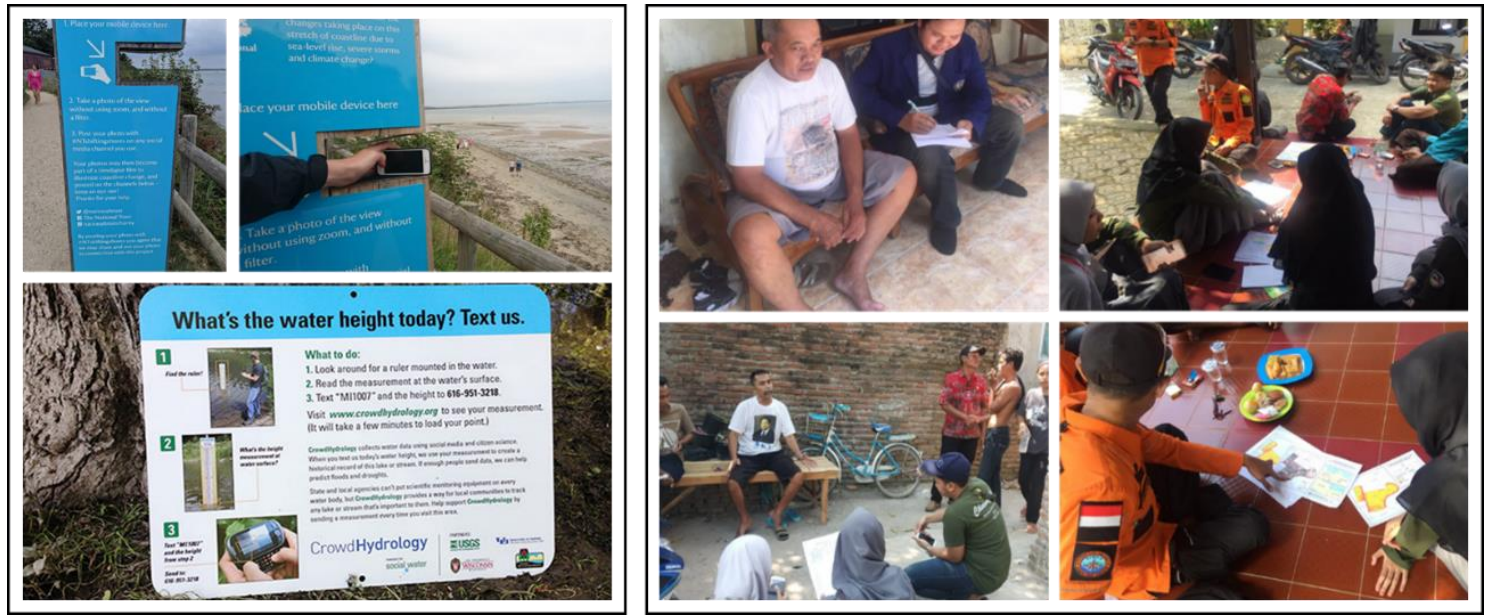

Gambar 2. Urun Daya Pengamatan Garis Pantai dan Ketinggian Banjir (kiri), Pemetaan Partisipatif Penanggulangan Banjir di Desa Ciledug Lor (kanan). (Sumber: Southworth \& Hope, 2019; Lowry \& Fienen, 2019; Dede et al., 2019)

Bila open data disediakan oleh pemerintah atau lembaga resmi sebagai wujud keterbukaan informasi, maka urun daya atau crowdsourcing memiliki ciri khas utama yakni berupa kesediaan masyarakat secara sukarela atas kesadaran mereka sendiri untuk mendokumentasikan dan mengumpulkan beragam data maupun informasi mengenai fenomena yang dianggap penting (Ar-Rahiem, 2019). Urun daya merupakan alternatif untuk memperoleh beragam data dan informasi mengenai SDAL yang efektif dan efisien bila dikoordinasikan dengan baik oleh perorangan atau lembaga yang memiliki wewenang, sehingga mekanisme maupun peralatan penunjangnya perlu disediakan. Pengumpulan data biasanya dilakukan dengan platform jejaring media sosial - mekanisme tagar dan mention - atau langsung ke laman tertentu yang menjadi server basis data untuk selanjutnya diolah oleh pihak berkepentingan (See, et al., 2016; Mezana et al., 2017). Ditinjau dari mekanismenya, kualitas dan keberhasilan urun daya sangat dipengaruhi oleh tingkat pendidikan, kesadaran kolektif, akses informasi, dan intervensi teknologi di tengah masyarakat. Penyebarluasan informasi secara daring maupun on the spot yang menarik mutlak diperlukan untuk mengajak masyarakat melakukan urun daya.

Selain memiliki banyak kelebihan, urun daya juga memiliki satu masalah utama yakni akurasi data dan informasi. Bila hanya mengandalkan perangkat smartphone, maka akurasi lokasi menjadi masalah tersendiri. Hal ini disebabkan masih sedikitnya perangkat smartphone yang dilengkapi dengan receiver Global Navigation Satellite System (GNSS) memadai untuk menangkap sinyal GPS (AS), GLONASS (Rusia), Beidou (Tiongkok), Galileo (Uni Eropa), QZSS (Jepang) dan lain sebagainya secara optimal (Widiawaty, 2019). Sebagian besar smartphone di pasaran hanya menyediakan receiver untuk menangkap sinyal GPS, sehingga lokasi yang terekam saat pengambilan data dalam urun daya akan memiliki distorsi antara 5 20 meter. Oleh sebab itu, lokasi yang menjadi sasaran dalam urun daya mesti di-plotting terlebih dahulu dengan perangkat receiver GNSS berakurasi tinggi misalnya menggunakan perangkat GNSS jenis real time kinetic (RTK) maupun smartphone yang mumpuni.

Metode lain yang dapat ditempuh untuk memperoleh data dan informasi terkait pengelolaan SDAL adalah pemetaan partisipatif. Menurut Ismail et al. (2019), pemetaan partisipatif merupakan metode untuk mendokumentasikan berbagai potensi spasial yang dilakukan secara aktif oleh masyarakat guna menghasilkan data untuk pengembangan wilayah. Pemetaan partisipatif menuntut peranan aktif dari peneliti, akademisi, pemerintah dan masyarakat setempat, serta lembaga swadaya masyarakat (LSM) untuk mencapai tujuan yang sama (Gambar 2). Pemetaan partisipatif dilandasi oleh asumsi bahwa masyarakat setempat 
sebagai subjek pengelola SDAL memiliki pengalaman dan mental maps yang berpotensi menghasilkan beragam informasi berharga (Sudaryatno, et al., 2017). Pemetaan partisipatif memiliki keunggulan dari segi akurasi, ketelitian, dan fleksibilitas penggunaan media. Metode ini juga dapat menjadi ajang bagi penyebaran pengetahuan dan keterampilan praktis bagi masyarakat terlibat, membangun interaksi sosial yang intensif, serta meningkatkan kesadaran masyarakat tentang pengelolaan SDAL. Meski begitu, pemetaan partisipatif memerlukan waktu yang lebih lama bila dibandingkan pengaksesan open data maupun urun daya, bahkan menjadi oxymoron bagi masyarakat tatkala penanganannya tidak dilakukan dengan bijak.

\section{KETERBATASAN INTEGRASI DAN SOLUSINYA DALAM PENGELOLAAN SDAL}

Open data, urun daya, dan pemetaan partisipatif sebenarnya memiliki beberapa kesamaan yakni semangat untuk berbagi, pemberdayaan masyarakat, pemberian nilai lebih terhadap data dan informasi, efisiensi biaya dan waktu, serta keterbukaan. Open data merupakan salah satu wujud good governance dalam pengelolaan SDAL oleh pemerintah yang seharusnya bisa ditiru oleh sektor swasta sebagai wujud pertanggungjawaban kepada publik. Adanya kesamaan tersebut menandakan ketiga metode ini berpotensi untuk diintegrasikan dalam rangka pengelolaan SDAL. Open data menyediakan beragam data dasar yang dapat diolah lebih lanjut untuk berbagai keperluan, misalnya citra satelit multi-spektral (Landsat, MODIS, CBERS, Sentinel), Synthetic Aperture Radar (SAR), Digital Elevation Model (DEM), jaringan jalan, batimetri, peta topografi (rupa bumi), polusi udara, kependudukan, kejahatan dan lain sebagainya (Samanta, et al., 2011; Dede, et al., 2017; Mohamed, 2017; Dede et al, 2019). Di tangan pihak yang mampu melakukan beragam analisis konvensional dan spasial, open data dapat menghasilkan banyak data maupun informasi berharga untuk beragam keperluan pengambilan keputusan (Hu, et al., 2017; Rusli et al., 2014). Khusus open data yang bersifat spasial, analisisnya dapat dibantu dengan pengolahan data berbasis komputasi awan yang dapat mengurangi konsumsi sumber daya terutama listrik, perangkat keras, serta kuota internet (Dede \& Widiawaty, 2020).

Kekurangan dari segi ketelitian dan updating pada open data bisa ditutupi melalui kegiatan urun daya (Tabel 1). Bahkan, salah satu metode klasifikasi citra satelit yakni supervised classification untuk pemantauan tutupan lahan, terumbu karang, perubahan garis pantai, bentuk muka bumi, dan kualitas perairan dapat ditunjang melalui kegiatan urun daya, asalkan sosialisasi tujuan dan mekanismenya tersampaikan secara jelas kepada masyarakat untuk terlibat. Bila berjalan dengan baik, integrasi antara open data dan urun daya sudah cukup untuk kegiatan pengelolaan SDAL hingga ke unit geografis berupa kecamatan, dimana urun daya berperan sebagai validator lapangan. Bila memerlukan data dan informasi lebih detail, pemetaan partisipatif merupakan opsi terbaik untuk meningkatkan ketelitian data. Pengamatan muka air tanah, pencemaran dan kualitas udara, valuasi SDAL, pengukuran batimetri, persebaran penyakit, surveillance, serta produktivitas lahan cocok bila dilakukan dengan metode ini (Corbet, 2009; Green, et al., 2016; Evans, 2018). Sosialisasi dan pemberian latihan singkat yang bersifat teknis mutlak diperlukan agar data yang dihasilkan dapat dipertanggungjawabkan dalam pemetaan partisipatif. Metode ini juga dapat dikembangkan lebih jauh menjadi kegiatan urun daya yang bisa dipantau jarak jauh, mengingat perkembangan teknologi smartphone dan tingkat pendidikan masyarakat memungkinkannya. Selain itu, data dan informasi yang berasal dari pemetaan partisipatif dapat menjadi input bagi pengembangan open data agar dapat digunakan kembali dalam proses pengelolaan SDAL seperti skema integrasi yang ditunjukkan pada Gambar 3. Kegiatan urun daya juga dapat dipadukan dengan data mining melalui fitur API yang terdapat pada berbagai jejaring sosial. 


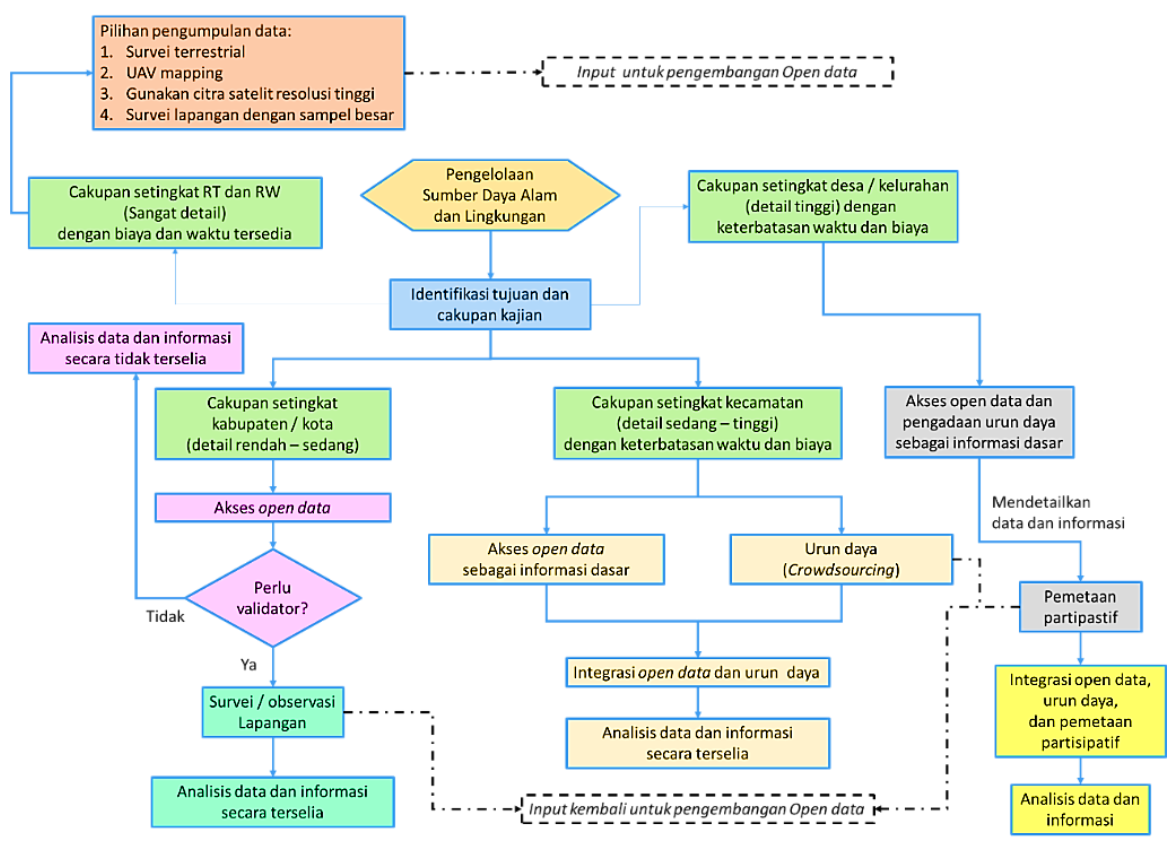

Gambar 3. Integrasi Open Data, Urun Daya, dan Pemetaan Partisipatif dalam Pengelolaan SDAL. (Sumber: Analisis Penulis, 2019)

Tabel 1. Keterbatasan Open Data, Urun Daya, dan Pemetaan Partisipatif dalam Pengelolaan SDAL beserta Solusinya

\begin{tabular}{|c|c|c|}
\hline Metode & Keterbatasan & Solusi Alternatif \\
\hline Open data & $\begin{array}{l}\text { 1. Ketelitian data dan informasi } \\
\text { maksimal hingga ke tingkat } \\
\text { kecamatan. } \\
\text { 2. Memerlukan kompetensi untuk } \\
\text { pengolahannya. } \\
\text { 3. Perizinan akses open data } \\
\text { cukup menantang, meskipun } \\
\text { hampir semuanya telah daring. }\end{array}$ & $\begin{array}{l}\text { 1. Perlu dilengkapi dengan observasi lapangan } \\
\text { (secara langsung maupun urun daya). Bisa } \\
\text { juga menggunakan data dan informasi } \\
\text { pembanding lainnya. } \\
\text { 2. Pemahaman terhadap tipe dan karakteristik } \\
\text { open data sangat diperlukan, termasuk } \\
\text { penguasaan perangkat lunak pendukung. } \\
\text { 3. Patuhi kebijakan setiap instansi dan negara } \\
\text { asal open data. }\end{array}$ \\
\hline Urun daya & $\begin{array}{l}\text { 1. Ketelitian data dan informasi } \\
\text { maksimal hingga ke tingkat } \\
\text { desa atau kelurahan. } \\
\text { 2. Risiko tidak ada input data dan } \\
\text { informasi dari masyarakat } \\
\text { cukup tinggi. } \\
\text { 3. Kualitas data dan informasi } \\
\text { rentan yang terkumpul tidak } \\
\text { sesuai kriteria. } \\
\text { 4. Instrumen pengambilan data } \\
\text { dan informasi beragam. }\end{array}$ & $\begin{array}{l}\text { 1. Pengecekan secara langsung pada waktu dan } \\
\text { lokasi tertentu harus dilakukan. } \\
\text { 2. Kemampuan komunikasi mutlak diperlukan } \\
\text { dan penyebarannya bisa dilakukan secara } \\
\text { daring, siapkan juga berbagai alat dan } \\
\text { instrumen untuk menarik partisipasi } \\
\text { masyarakat seperti papan informasi, tanda } \\
\text { lokasi pengambilan data, dan lainnya. } \\
\text { Pelibatan media massa yang kredibel kadang } \\
\text { diperlukan. } \\
\text { Perlu pemahaman untuk analisis metadata } \\
\text { dan data quality. }\end{array}$ \\
\hline $\begin{array}{l}\text { Pemetaan } \\
\text { partisipatif }\end{array}$ & $\begin{array}{l}\text { 1. Memerlukan waktu dan sumber } \\
\text { daya manusia yang cukup } \\
\text { banyak. } \\
\text { 2. Kemampuan SDM di tengah } \\
\text { masyarakat beragam. } \\
\text { 3. Adanya perbendaan persepsi } \\
\text { dan mental maps. }\end{array}$ & $\begin{array}{l}\text { 1. Ajak pihak pemerintah setempat, LSM, dan } \\
\text { sekolah tingkat menengah atas / sederajat } \\
\text { sebagai subjek untuk menunjang kegiatan ini. } \\
\text { 2. Adakan sosialisasi dan pelatihan teknis } \\
\text { bersama masyarakat. } \\
\text { 3. Siapkan data pendukung yang memicu } \\
\text { penyamaan persepsi dan mental maps } \\
\text { masyarakat, di sini open data dapat } \\
\text { digunakan sebagai informasi penunjang. }\end{array}$ \\
\hline
\end{tabular}

Meski begitu, baik open data, urun daya, dan pemetaan partisipatif maupun integrasi ketiganya sangat sulit untuk bisa memenuhi kajian pengelolaan SDAL pada level sangat detail, 
sehingga solusinya kembali ke pengumpulan data secara konvensional - meskipun dalam beberapa fenomena pemanfaatan analisis geostatistik dengan data hasil urun daya dan pemetaan partisipatif masih memungkinkan untuk menjangkaunya (Widiawaty et al., 2018; Setiawan, et al., 2019). Integrasi ketiganya diharapkan mampu menjadi solusi dan input bagi pengambilan keputusan terkait pengelolaan SDAL, terlebih bila SIG sebagai alat turut dilibatkan secara luas untuk analisis spasial. Apabila berjalan dengan baik, integrasi open data, urun daya, dan pemetaan partisipatif berpotensi membentuk citizen science dan contribution of self-data.

\section{KESIMPULAN}

Pengelolaan SDAL merupakan kegiatan sepanjang masa yang dilakukan oleh manusia sebagai bagian dari pembangunan. Pengelolaan SDAL berkelanjutan kerap menghadapi kendala dari segi pemerolehan data dan informasi terkait yang disertai dengan keterbatasan waktu, biaya, maupun tenaga terutama dialami oleh negara-negara berkembang. Pemanfaatan open data yang dipadukan dengan kegiatan urun daya dan pemetaan partisipatif dapat menjadi solusi jitu asalkan pemahaman terhadap ketiganya mumpuni. Dengan beragam keuntungannya, integrasi ketiganya mampu memberdayakan masyarakat untuk senantiasa terlibat dalam kegiatan pengelolaan SDAL secara langsung dari tahap perencanaan, pelaksanaan, hingga monitoring dan evaluasi.

\section{DAFTAR PUSTAKA}

Amaru, K., Asdak, C. and Balia, R. 2013. Penyuluhan Pengenalan Peta dan Identifikasi Potensi Daerah untuk Pembuatan Peta Potensi Desa di Desa Jatimekar dan Desa Cijati Kecamatan Situraja Kabupaten Sumedang. Dharmakarya, 2 (1), 32-40.

Ar-Rahiem, M. M. 2019. Urun Daya dalam Sains. https://malikarrahiem.com/urundaya-dalam-sains. [diakses 18 September 2019].

Badiee, S. 2017. Open Data: Better Data, Better Lives. Proceeding of Seminar on Emerging Issues, New York.

Christanto, J. 2014. Konservasi Sumber Daya Alam dan Lingkungan. Universitas Terbuka, Jakarta.

Corbet, J. 2009. Good Practices in Participatory Mapping. IFAD, Roma.

Dede, M. and Widiawaty, M. A. 2020. Utilization EOS Platform as Cloud-based GIS to Analyze Vegetation Greenness in Cirebon Regency, Indonesia. Journal of Information Technology and Its Utilization, 3 (1), 1-4.

Dede, M., Pramulatsih, G. P., Widiawaty, M. A. and Ati, A. 2019. Dinamika Suhu Permukaan dan Kerapatan Vegetasi di Kota Cirebon. Jurnal Meteorologi Klimatologi dan Geofisika, 6 (1), 23-31.

Dede, M., Setiawan, I. and Mulyadi, A. 2017. Application GIS to Analyse Crime Risk in Bandung. Proceeding of 2nd International Conference on Sociology Education, 1 (1), 597-602.

Dede, M., Widiawaty, M. A., Pramulatsih, G. P., Ismail, A., Ati, A. and Murtianto, H. 2019. Integration of Participatory Mapping, Crowdsourcing and Geographic Information System in Flood Disaster Management (Case Study Ciledug Lor, Cirebon). Journal of Information Technology and Its Utilization 2 (2), 44-47

Dede, M., Widiawaty, M., Setiawan I. and Huda, N. 2019. Integrasi AHP dan Sistem Informasi Geografis untuk Analisis Potensi Kerawanan Illegal Fishing di Indonesia. Jurnal Sains Informasi Geografi, 2 (2), 8-17.

Dietrich, D., Gray, J., McNamara, T., Poikola, A., Pollock, R., Tait, J. and Zijlstra, T. 2009. Buku Pegangan Open Data. Open Knowledge Foundation, Cambridge.

Evans, W. P. 2018. Participatory Mapping Toolkit: A Guide for Refugee Contexts. Humanitarian OpenStreetMap Team, New York.

GN-PSDA. 2015. Gerakan Nasional Penyelamatan Sumber Daya Alam Sektor Kelautan, Pertambangan, Kehutanan dan Perkebunan. GN-PSDA dan Istana Negara, Jakarta. 
Green, E. P., Warren, V. R., Broverman, S., \& Ogwang, B. and Puffer, E. S. 2016. Participatory Mapping in Low-Resource Settings: Three Novel Methods Used to Engage Kenyan Youth and Other Community Members in Community-based HIV Prevention Research. Glob. Public Health. 11 (5), 583-599.

Habibullah. 2007. Pemanfaatan Lahan dan SDM dalam Pembangunan Masyarakat Desa Sekitar Hutan di Kabupaten Batanghari Propinsi Jambi. Jurnal Penelitian dan Pengembangan Kesejahteraan Sosial, 12 (2), 33-43.

Hendawati, D. 2012. Sumber Daya Alam dan Lingkungan Hidup. Program Dual-Modes Universitas Pendidikan Indonesia, Bandung.

Hu, Z., Peng, J., Hou, Y. and Shan, J. 2017. Evaluation of Recently Released Open Global Digital Elevation Models of Hubei, China. Remote Sensing, 9, 262.

Ismail, A., Afriani, A. R., Himayah, S. and Malik, Y. 2019. Partcipatory Mapping for Community-based Watershed Management, Lesson Learn from Central Java and West Nusa Tenggara. IOP Conf. Series: Earth and Environmental Science, 286, 01224.

Ismail, A., Dede, M. and Widiawaty, M. A. 2020. Urbanisasi dan HIV di Kota Bandung (Perspektif Geografi Kesehatan). Buletin Penelitian Kesehatan, 48 (2), 139-146.

JMC IT. 2019. Perkembangan Open Data di Indonesia. https://www.jmc.co.id/blog/ Perkembangan-Open-Data-di-Indonesia/. [diakses 18 September 2019].

Kehati. 2009. Materi Kursus Inventarisasi Flora dan Fauna Taman Nasional Meru Betiri. Yayasan Kehati, Malang.

Lowry, C. and Fienen, M. 2019. Crowdhidrology. http://www.crowdhydrology.com/ about/how-it-works/. [diakses 18 September 2019].

Mezzana, D., Quint, G., Leeuwenhoek, J. W., Dell'Oro, A., Dell'Oro, L., Caiati, G., Marta, F. and Alfonsi, A. 2017. Crisis Mapping and Crowdsourcing in Flood Management. World Meteorological Organization, Geneva.

Miller, G. T., dan Spoolman, S. 2011. Living in the Environment: Principles, Connections, and Solutions. Brooks-Cole, Belmont.

Misra, P., Avtar, R. and Takeuchi, W. 2018. Comparison of Digital Building Height Models Extracted from AW3D, TanDEM-X, ASTER, and SRTM Digital Surface Models over Yangon City. Remote Sensing, 10, 12.

Mohamed, M. A. 2017. Analysis of Digital Elevation Model and Landsat data Using Geographic Information System for Soil Mapping in Urban Areas. Natural Resources, 8 (12), 767-787.

Neupane, P., Balami, N., Khanal, K., Ghimire, S., Ghimire, F. and S, Ghimire. 2017. Open Data Manual. Open Knowledge Nepal, Kathmandu.

Open Data Watch. 2018. Overcoming Open Data Worries. https://opendatawatch. com/blog/overcoming-open-data-worries/. [diakses 18 September 2019].

Rusli, N., Majid, M. R. and Din, A. H. M. 2014. Google Earth's Derived Digital Elevation Model: a Comparative Assessment with Aster and SRTM Data. IOP Conf. Series: Earth and Environmental Science, 18, 012065.

Samanta, S., Pali, D. K., Lohar, D. and Pali, B. 2011. Preparation of Digital Datasets on Land Use/Land Cover, Soil and Digital Elevation Model for Temperature Modelling Using Remote Sensing and GIS Techniques. Indian Journal of Science and Technology, 4 (6), 636-642.

See, L., Mooney, P., Foody, G., Bastin, L., Comber, A., Estima, J., Fritz, S., Kerle, N., Jiang, B. and Laakso, M. 2016. Crowdsourcing, Citizen Science or Volunteered Geographic Information? The Current State of Crowdsourced. ISPRS Int. J. GeoInf., 5 (55), 1-23.

Sidauruk, R. and Hamdi, M. 2015. Mendorong Pembentukan Kebijakan dan Implementasi Data Terbuka di Indonesia. Institute for Criminal Justice Reform, 
Jakarta.

Soemarwoto, O. 1985. Ekologi Lingkungan Hidup dan Pembangunan. Djambatan, Jakarta.

Southworth, P. and Hope, C. 2019. National Trust Asks Beach-Goers to Post Pictures on Instagram to Help Monitor Coastal Erosion. https://www.telegraph.co.uk /news/2019/08/18/national-trust-asks-beach-goersto-post-pictures-instagram-help/. [diakses 18 September 2019].

Sunlight Foundation. 2010. Ten Principles for Opening up Government Information. http://sunlightfoundation.com/policy/documents/ten-open-data-principles/. [diakses 18 September 2019].

Widiawaty, M. A. 2019. Mari Mengenal Sains Informasi Geografis. Aria Mandiri Group, Bandung.

Widiawaty, M. A. and Dede, M. 2018. Pemodelan Spasial Bahaya dan Kerentanan Bencana Banjir di Wilayah Timur Kabupaten Cirebon. Jurnal Dialog Penanggulangan Bencana, 9 (2), 142-153.

Widiawaty, M. A., Dede, M. and Ismail, I. 2018. Comparative Study Modeling of Ground Water Using Geographic Information System in Kayuambon Village, Bandung Barat Regency. Jurnal Geografi Gea, 18 (1), 63-71.

Wijaya, M. N. Q. 2014. Apa itu Data Terbuka. https://www.big.go.id/assets/ download/artikel/BIG-ApaItuDataTerbuka.pdf. [diakses 18 September 2019].

Young, A. and Verhulst, S. 2016. The Global Impact of Open Data. O'Reilly Media Inc., Sebastopol. 